\title{
GMR
}

\section{Single nucleotide polymorphisms associated with growth traits in Jinghai yellow chickens}

\author{
M.A. Abdalhag ${ }^{1,2}$, T. Zhang ${ }^{1,2}$, Q.C. Fan ${ }^{1,2}$, X.Q. Zhang ${ }^{1,2}$, G.X. Zhang ${ }^{1,2}$, \\ J.Y. Wang ${ }^{1,2}$, Y. Wei ${ }^{1,2}$ and Y.J. Wang ${ }^{3}$ \\ ${ }^{1}$ College of Animal Science and Technology, Yangzhou University, \\ Yangzhou, Jiangsu, China \\ ${ }^{2}$ Key Laboratory for Animal Genetics, Breeding, Reproduction and \\ Molecular Design of Jiangsu Province, Yangzhou, Jiangsu, China \\ ${ }^{3}$ Jiangsu Jinghai Poultry Group Co., Ltd., Nantong, Jiangsu, China \\ Corresponding author: J.Y. Wang \\ E-mail: jywang@yzu.edu.cn \\ Genet. Mol. Res. 14 (4): 16169-16177 (2015) \\ Received August 15, 2015 \\ Accepted October 2, 2015 \\ Published December 8, 2015 \\ DOI http://dx.doi.org/10.4238/2015.December.8.6
}

\begin{abstract}
Body weight is one of the most important economic traits in the poultry industry. In the present study, a custom SNP Beadchip was used to analyze the association between those 15 SNPs and 12 growth traits of Jinghai yellow chickens, and other important genetic parameters were also calculated and analyzed. The results indicated that nine of the 15 SNPs were associated with growth traits in Jinghai yellow chickens $(P<0.05)$, and the identified SNPs were also in linkage disequilibrium. Five of the nine identified SNPs were mainly associated with all of the growth traits, which indicated that those five SNPs might have significant influence on Jinghai yellow chicken growth traits. Polymorphism information content (PIC) analyses indicated that five of the nine SNPs exhibited moderate polymorphism $(0.25$ $<$ PIC < 0.5), which reflected intermediate genetic diversity. Six candidate genes surrounding the significant SNPs were obtained and subjected to Gene Ontology annotation analyses and pathway analyses. The functions of six important candidate genes (SETDB2, ATP7B, INTS6, KPNA3, DLEU7, and FOXO1A) were discussed. The present study provided basic data for
\end{abstract}


marker-assisted selection in Jinghai yellow chickens.

Key words: Jinghai yellow chicken; Growth traits; Linkage disequilibrium; GWAS

\section{INTRODUCTION}

In the poultry industry, growth is considered one of the most important economic traits. Much effort has been invested to improve growth traits, especially regarding genetic improvement. Therefore, work towards the genetic improvement of growth traits is essential, and the genetic improvement in chicken growth traits has made great progress during the past few years. However, most of the work was conducted using traditional breeding methods. Marker-assisted selection (MAS) is a new method based on molecular markers, which can shorten the breeding process and save a lot of time and money ( $\mathrm{Lu}$ and $\mathrm{Wu}, 2002)$. Therefore, it is essential to exploit and identify new markers that could be used in breeding work.

Many traditional methods are currently used to detect SNPs, including DNA sequencing, Restriction Fragment Length Polymorphism (RFLP), Single Stranded Conformational Polymorphism (SSCP), and denaturing high performance liquid chromatography (DHPLC); however, these methods lack speed, efficiency, and automation. Recently developed DNA Beadchip technology is a method used to detect DNA sequence variation, and it is widely used in studies of human disease and economically important animal traits. In chickens, many genome-wide association studies (GWAS) were conducted using the Illumina 60K SNP Beadchip. Using this method, major loci associated with growth (Gu et al., 2011; Xie et al., 2012), egg production (Liu et al., 2011; Wolc et al., 2012), rumpless and ear-tufted traits (Noorai et al., 2012), body composition and meat quality (Liu et al., 2013), resistance to Marek's disease (Li et al., 2013), and immune responses to Newcastle disease virus (Luo et al., 2013) were identified.

A previous study observed 15 SNPs (Table 1), detected by SNP Beadchip analysis, in a 168.5-170.0 Mb region of GGA1 that influenced chicken growth traits $(P<0.05)$ (Xie et al., 2012). In the present study, a custom SNP Beadchip was used to analyze the association between those 15 SNPs and 12 growth traits of Jinghai yellow chickens. Furthermore, major population genetic parameters were calculated, including gene frequency, genotype frequency, and effective number of alleles, and the linkage disequilibrium (LD) and haplotypes of the SNPs were also analyzed. Ensembl and NCBI were used to obtain genes within this region with 1-Mb windows surrounding each SNP (SNP position $\pm 0.5 \mathrm{Mb}$ ). We aimed to identify new SNPs and candidate genes associated with growth traits and to provide basic data for MAS of Jinghai yellow chickens.

\section{MATERIAL AND METHODS}

\section{Population and sample collection}

A total of 396 blood samples were collected from female Jinghai yellow chickens, and all samples were randomly selected from the same batch at the Jiangsu Jinghai Poultry Industry Group Co., Ltd. All experimental chickens were hatched on the same day, and were subsequently raised in floor pens with access to water and feed (commercial diets meeting NCR requirements). Bodyweight data were recorded at the following ages (in weeks): 2 (BW2), 4 (BW4), 6 (BW6), 8 
(BW8), 10 (BW10), 12 (BW12), 14 (BW14), and 16 (BW16). Average daily weight gains between ages 0-4 (ADG4), 4-8 (ADG8), 8-12 (ADG12), and 12-16 (ADG16) weeks were calculated, and the basic growth trait statistics are shown in Table 2.

\begin{tabular}{lcr}
\multicolumn{2}{c}{ Table 1. Locations and relevant traits of 15 SNPs. } & \\
\hline SNP ID & Chromosome & Position (bp) \\
\hline rs316142388 & 1 & 168504143 \\
rs15497877 & 1 & 168589760 \\
rs15497910 & 1 & 168609931 \\
rs314214528 & 1 & 168841831 \\
rs13972304 & 1 & 168931358 \\
rs313583074 & 1 & 168993046 \\
rs13553164 & 1 & 169026310 \\
rs14917305 & 1 & 169093530 \\
rs317063416 & 1 & 169121392 \\
rs14917647 & 1 & 169403027 \\
rs13553485 & 1 & 169614824 \\
rs315321005 & 1 & 169803697 \\
rs13973515 & 1 & 169868287 \\
rs314628319 & 1 & 169941464 \\
rs314967487 & 1 & 169978701 \\
\hline
\end{tabular}

Table 2. Basic growth-trait statistics for the experimental chickens.

\begin{tabular}{lccccc}
\hline Traits & Sample size & Maximum & Minimum & Mean & Standard deviation \\
\hline BW2 & 300 & 126.0 & 40.0 & 85.6 & 13.5 \\
BW4 & 348 & 324.0 & 106.0 & 205.3 & 29.9 \\
BW6 & 343 & 495.0 & 200.0 & 330.2 & 52.1 \\
BW8 & 293 & 695.0 & 310.0 & 513.5 & 72.7 \\
BW10 & 1290.0 & 405.0 & 706.4 & 106.7 \\
BW12 & 288 & 1170.0 & 605.0 & 870.7 & 100.5 \\
BW14 & 273 & 1480.0 & 680.0 & 1042.3 & 113.8 \\
BW16 & 335 & 1502.0 & 725.0 & 1123.5 & 124.8 \\
ADG4 & 398 & 20.7 & 6.4 & 12.3 & 5.2 \\
ADG8 & 300 & 36.6 & 7.9 & 22.0 & 4.3 \\
ADG12 & 255 & 45.0 & 7.5 & 25.7 & 4.8 \\
ADG16 & 252 & 41.1 & 5.6 & 18.2 & 5.2 \\
\hline
\end{tabular}

The unit of body weight (BW) is g. The unit of average daily weight gain (ADG) is g/day. BW2, BW4, BW6, BW8, BW10, BW12, BW14, and BW16 are the body weights at ages 2, 4, 6, 8, 10, 12, 14, and 16 weeks, respectively. ADG4, ADG8, ADG12, and ADG16 are the average daily gains during weeks 0-4, 4-8, 8-12, and 12-16, respectively.

\section{DNA extraction and genotyping}

Genomic DNA was extracted using the Dzup Genomic DNA Isolation Reagent Kit from Sangon Biotech Co., Ltd. (Shanghai, China). The DNA concentration and quality were quantified by spectrophotometry and agarose gel electrophoresis. The quality control criterion was the genome DNA concentration $>100 \mathrm{ng} / \mathrm{mL}, 1.7<\mathrm{OD}_{260} / \mathrm{OD}_{280}$ value $<1.8$. Subsequently, the qualified DNA samples were sent to DNA LandMarks Inc. (Quebec, Canada) for genotyping using the custom SNP Beadchip. Genotyping was carried out according to the Beadchip Assay Kit (Illumina, USA) protocol. The genotypes of the 15 SNPs were obtained by the SNP ID.

\section{Statistical analysis}

Statistical analyses were conducted using SPSS 19.0 version, and the general linear 
model (GLM) procedure was used to analyze the associations between 155 SNPs and 12 growth traits according to the following model:

$$
\mathrm{Y}=\mu+\mathrm{G}_{\mathrm{i}}+\mathrm{e}_{\mathrm{ij}}
$$

where, $Y$ is the corrected phenotypic value of the growth traits, $\mu$ is the overall mean, $G_{i}$ is the single-locus SNP genotype effect, and $e_{i j}$ is a random residual.

Allele frequency, genotype frequency, efficient allelic number $\left(N_{\mathrm{E}}\right)$, polymorphism information content (PIC), and chi-square tests were calculated using the POPGENE program (Zane et al., 2002). LD was calculated using the SHEsis program (Shi et al., 2005), and haplotypes were analyzed using Phase version 2.1.

\section{RESULTS}

\section{Association analysis}

The results of the association analysis between SNPs and growth traits showed that nine out of the 15 SNPs were associated with Jinghai yellow chicken growth traits $(P<0.05)$ (Table 3). Seven of the nine SNPs were found to be associated with more than two traits, and the other two SNPs (rs14917305 and rs13553485) effected ADG16 and BW2, respectively. The results indicated that SNPs rs15497877, rs13972304, rs13553164, rs14917647, and rs13973515 were associated with body weight at both the early (2-8 weeks) and late (10-16 weeks) growth stages. SNPs rs314214528 and rs13553485 were associated with body weight at the early growth stage (2-8 weeks), while rs316142388 was strongly associated with body weight at the late growth stage (10-16 weeks). SNPs rs15497877, rs13972304, and rs14917647 were associated with average daily weight gains at both early (4-8 weeks) and late (12-16 weeks) growth stages. Moreover, SNPs rs314214528 and rs13973515, were associated with average daily weight gains at the early growth stage (4-8 weeks), while rs14917305 was associated with average daily weight gains at the late growth stage (12-16 weeks).

Table 3. Association analysis between 9 SNPs and 12 growth traits.

\begin{tabular}{|c|c|c|c|c|c|c|c|c|c|c|c|c|}
\hline SNP ID & BW2 & BW4 & BW6 & BW8 & BW10 & BW12 & BW14 & BW16 & ADG4 & ADG8 & ADG12 & ADG16 \\
\hline rs316142388 & 0.367 & 0.372 & 0.322 & 0.791 & 0.402 & $0.021^{*}$ & $0.023^{*}$ & $0.001^{*}$ & 0.146 & 0.681 & 0.094 & 0.366 \\
\hline rs15497877 & 0.368 & 0.181 & $0.026^{*}$ & $0.040^{*}$ & 0.113 & $0.002^{*}$ & $0.007^{*}$ & 0.012 & 0.327 & $0.026^{*}$ & $0.033^{*}$ & 0.354 \\
\hline rs314214528 & 0.127 & $0.007^{*}$ & $0.002^{*}$ & 0.450 & 0.131 & 0.270 & 0.704 & 0.219 & $0.026^{*}$ & 0.842 & 0.398 & 0.737 \\
\hline rs13972304 & 0.930 & 0.094 & $0.001^{*}$ & 0.197 & 0.302 & 0.247 & 0.172 & $0.009^{*}$ & $0.030^{*}$ & $0.080^{*}$ & 0.761 & $0.040^{*}$ \\
\hline rs13553164 & $0.035^{\star}$ & 0.223 & 0.248 & 0.224 & $0.025^{*}$ & 0.882 & 0.878 & 0.523 & 0.174 & 0.465 & 0.511 & $0.040^{*}$ \\
\hline rs14917305 & 0.198 & 0.436 & 0.176 & 0.161 & 0.696 & 0.531 & 0.570 & 0.188 & 0.263 & 0.852 & 0.354 & $0.011^{*}$ \\
\hline rs14917647 & 0.057 & 0.004 & 0.364 & $0.019^{*}$ & 0.610 & 0.067 & $0.036^{*}$ & $0.002^{*}$ & $0.011^{*}$ & 0.104 & 0.069 & $0.005^{*}$ \\
\hline rs13553485 & $0.025^{*}$ & 0.569 & 0.257 & 0.932 & 0.775 & 0.586 & 0.519 & 0.062 & 0.302 & 0.870 & 0.643 & 0.056 \\
\hline rs13973515 & 0.360 & 0.266 & 0.141 & $0.022^{*}$ & $0.041^{*}$ & 0.509 & $0.013^{*}$ & $0.013^{*}$ & 0.764 & $0.034^{*}$ & 0.754 & 0.130 \\
\hline
\end{tabular}

*Indicates significance $(P<0.05)$.

\section{Genetic parameters of significant SNPs}

Allele frequency, genotype frequency, $N_{E}$, PIC, and chi-square tests were calculated (Table 4A and B). The results showed that SNPs rs13553164, rs14917647, and rs13973515 had missing 
genotypes. PIC analysis results indicated that SNPs rs316142388, rs314214528, rs13972304, and rs 13553485 exhibited low polymorphism (PIC $<0.25$ ), and the other five SNPs exhibited moderate polymorphism $(0.25<\mathrm{PIC}<0.5$; mean PIC $=0.201)$. The chi-square test results indicated that all nine SNPs were in Hardy-Weinberg equilibrium, with the exception of rs 15497877.

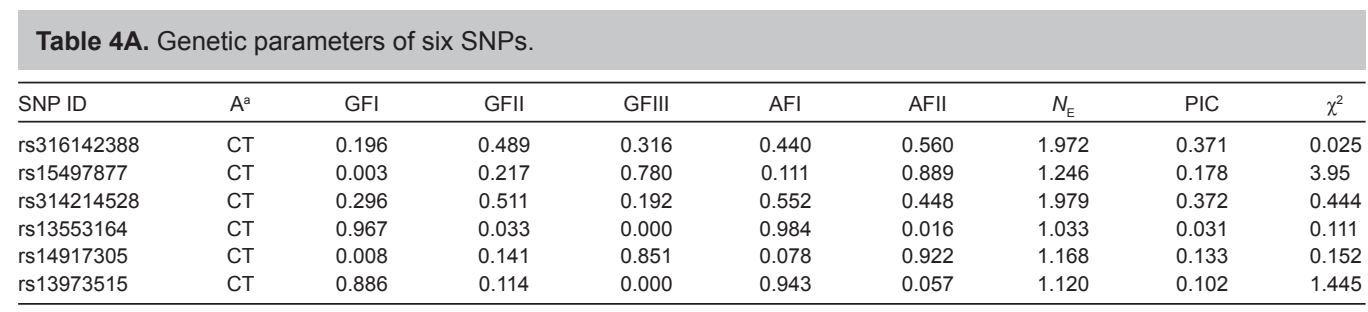

$\mathrm{A}^{\mathrm{a}}=$ allele, GF = genotype frequency, AF = allele frequency. GFI, GFII, and GFIII indicate the genotype frequencies of $\mathrm{CC}, \mathrm{TC}$, and TT, respectively, and AF1 and AFII indicate the allele frequencies of $\mathrm{C}$ and $\mathrm{T}$, respectively. $\chi_{0.05}^{2}(\mathrm{~d} . \mathrm{f} .=1$ ) $=3.84, \chi_{0.01}^{2}($ d.f. $=1)=6.64$.

\begin{tabular}{|c|c|c|c|c|c|c|c|c|c|}
\hline SNP ID & $A$ & GFI & GFII & GFIII & AFI & AFII & $N_{\mathrm{E}}$ & PIC & $\chi^{2}$ \\
\hline rs13972304 & $A C$ & 0.091 & 0.460 & 0.449 & 0.321 & 0.679 & 1.773 & 0.341 & 0.606 \\
\hline rs14917647 & $A C$ & 0.000 & 0.033 & 0.967 & 0.016 & 0.984 & 1.033 & 0.031 & 0.111 \\
\hline rs13553485 & $A C$ & 0.477 & 0.439 & 0.083 & 0.697 & 0.303 & 1.731 & 0.333 & 0.494 \\
\hline
\end{tabular}

$\mathrm{A}=$ allele, GF = genotype frequency, $\mathrm{AF}=$ allele frequency. GFI, GFII, and GFIII indicate the genotype frequencies of $\mathrm{AA}, \mathrm{AC}$, and $\mathrm{CC}$, respectively, and AF1 and AFII indicate the allele frequencies of $\mathrm{C}$ and $\mathrm{T}$, respectively. $\chi_{0.05}^{2}(\mathrm{~d} . \mathrm{f} .=1)$ $=3.84, \chi_{0.01}^{2}($ d.f. $=1)=6.64$.

\section{Linkage disequilibrium and haplotype analysis}

LD analysis results (Table 5) indicated that SNPs rs13553164 and rs13972304 were in complete linkage $\left(D^{\prime}=1\right)$. SNPs rs13553164, rs14917647, rs14917647, rs13973515, and rs13973515 were in close linkage ( $D^{\prime}>0.99$ ) with rs314214528, rs314214528, rs13972304, rs13553485, and rs13553485, respectively. Moreover, SNPs rs13972304 and rs14917647 were also in linkage $\left(D^{\prime}>0.90\right)$ with rs314214528 and rs14917305, respectively. The haplotype analysis results (Table 6) showed that 53 haplotypes were successfully established, and 12 of those haplotypes were present at greater than 2.0\%. The TTTCCTCAC haplotype accounted for $32.4 \%$ of all haplotypes, and CTCCCTCAC and CTCACTCCC haplotypes accounted for 13.9 and $12.8 \%$, respectively.

\begin{tabular}{|c|c|c|c|c|c|c|c|c|}
\hline SNP & rs15497877 & rs314214528 & rs13972304 & rs13553164 & rs14917305 & rs14917647 & rs13553485 & rs13973515 \\
\hline rs316142388 & 0.371 & 0.670 & 0.284 & 0.506 & 0.256 & 0.360 & 0.333 & 0.484 \\
\hline rs15497877 & - & 0.771 & 0.305 & 0.212 & 0.231 & 0.008 & 0.210 & 0.897 \\
\hline rs314214528 & - & - & 0.977 & 0.999 & 0.788 & 0.993 & 0.859 & 0.560 \\
\hline rs13972304 & - & - & - & 1.000 & 0.579 & 0.999 & 0.632 & 0.993 \\
\hline rs13553164 & - & - & - & - & 0.088 & 0.207 & 0.153 & 0.134 \\
\hline rs14917305 & - & - & - & - & - & 0.911 & 0.366 & 0.009 \\
\hline rs14917647 & - & - & - & - & - & - & 0.174 & 0.584 \\
\hline rs13553485 & - & - & - & - & - & - & - & 0.996 \\
\hline
\end{tabular}




\begin{tabular}{|c|c|c|}
\hline Haplotype & Sequence & Haplotype frequency \\
\hline hapl & ТTТССТСАС & 0.324 \\
\hline hap2 & СТСССТСАС & 0.139 \\
\hline hap3 & СТСАСТССС & 0.128 \\
\hline hap4 & TTСАСТССС & 0.061 \\
\hline hap5 & СТTССТСAC & 0.059 \\
\hline hap6 & TTTССТСAT & 0.034 \\
\hline hap7 & TTCACTCAC & 0.031 \\
\hline hap8 & СТСACTCAC & 0.029 \\
\hline hap9 & ТTСССТССС & 0.026 \\
\hline hap10 & СТСАССССС & 0.024 \\
\hline hap11 & СТСССТССС & 0.023 \\
\hline hap12 & TTCCСTCAC & 0.021 \\
\hline
\end{tabular}

\section{Bioinformatic analysis of candidate genes}

Six candidate genes (Table 7) were obtained and subsequently subjected to Gene Ontology (GO) annotation analyses (Table 8), and the pathways of the candidate genes were analyzed using the KEGG database. The results indicated that the SET domain bifurcated 2 gene (SETDB2) was a histone-lysine N-methyltransferase that participated in the lysine degradation pathway (ko00310). The Forkhead box 01 gene (FOXO1) participated in the FoxO signaling pathway (ko04068), the transcriptional misregulation in cancer pathway (ko05202), the AMPK signaling pathway (ko04152), the insulin signaling pathway (ko04910), the thyroid hormone signaling pathway (ko04919), and the prostate cancer pathway (ko05215).

Table 7. Allele frequency of five groups and proximal genes.
\begin{tabular}{lcccc}
\hline SNPs & Favorable alleles & Chromosome & Position & Proximal gene \\
\hline rs316142388 & C & 1 & 168504143 & SETDB2 \\
rs15497877 & C & 1 & 168589760 & KPNA3 \\
rs314214528 & $\mathrm{C}$ & 1 & 168841831 & Unknown \\
rs13972304 & $\mathrm{A}$ & 1 & 168931358 & Unknown \\
rs13553164 & $\mathrm{T}$ & 1 & 169026310 & $96.808 \mathrm{~kb}$ D DLEU7 \\
rs14917305 & $\mathrm{C}$ & 1 & 169093530 & $29.588 \mathrm{~kb}$ D DLEU7 \\
rs14917647 & $\mathrm{A}$ & 1 & 169403027 & INTS6 \\
rs13553485 & $\mathrm{C}$ & 1 & 169614824 & ATP7B \\
rs13973515 & $\mathrm{T}$ & & 169868287 & $8.765 \mathrm{~kb}$ D FOXO1 \\
\hline
\end{tabular}

\begin{tabular}{llll}
\multicolumn{2}{l}{ Table 8. GO annotation of candidate genes. } & & \\
\hline Gene name & & GO annotation & \\
\cline { 2 - 4 } & Cellular component & Molecular function & Biological process \\
\hline SETDB2 & Cell nucleus, chromosome & Zinc ion binding, DNA binding & Histone H3-K9 methylation, chromosome segregation \\
KPNA3 & Cytoplasm, nucleus & $\begin{array}{l}\text { Protein C-terminus binding, } \\
\text { protein transporter activity }\end{array}$ & Protein import into nucleus \\
DLEU7 & Subcellular entity & $\begin{array}{l}\text { Unknown } \\
\text { Unknown }\end{array}$ & Unknown \\
INTS6 & Integrator complex, actin cytoskeleton & Copper ion binding & Copper ion export, cellular copper ion homeostasis \\
ATP7B & Trans-Golgi network, perinuclear region of cytoplasm & $\begin{array}{l}\text { Protein phosphatase 2A binding, } \\
\text { ubiquitin protein ligase binding }\end{array}$ & $\begin{array}{l}\text { Negative regulation of apoptotic, autophagy, } \\
\text { gluconeogenesis and protein catabolic process, } \\
\text { cellular response to starvation }\end{array}$ \\
\hline
\end{tabular}




\section{DISCUSSION}

Growth is a very complex trait that is regulated by a number of genes and pathways, and more than 1500 quantitative trait loci have been found to be associated with chicken growth traits (Liu et al., 2008; Uemoto et al., 2009; Wahlberg et al., 2009; Gu et al., 2011). In the present study, 15 previously identified SNPs in GGA1 were detected using a custom Beadchip analysis. We found that only nine of the 15 SNPs were associated with growth traits in Jinghai yellow chickens, which was not consistent with the previous study. This result might be largely due to the breed difference. Five of the nine SNPs were mainly associated with all of the studied growth traits in our experiment, which indicated that those five SNPs might significantly influence Jinghai yellow chicken growth traits. The accuracy of the GWAS results was affected by the total sample number as well as the number of samples with different genotypes. In the present study, SNPs rs 13553164 , rs14917647, and rs13973515 were missing genotypes in Jinghai yellow chickens, which might lead to false positives (Cardon and Bell, 2001). Therefore, more samples are needed if further studies are conducted.

$N_{\mathrm{E}}$ and PIC are import group genetic parameters that are used to show the size of intrapopulation genetic variation (Tao et al., 2008). The results of $N_{E}$ and PIC analyses showed that five out of the nine SNPs exhibited low polymorphism, while the other four SNPs exhibited moderate polymorphism. The mean of PIC value was 0.210 , which was relatively low. Therefore, selection should be continued in order to increase favorable allele frequencies in Jinghai yellow chickens. All of the SNPs were found to be in Hardy-Weinberg equilibrium $\left(\chi^{2}<3.84\right)$, with the exception of rs15497877, and this might be due to artificial breeding selection.

LD analysis is widely used in genetic parameter calculations, gene mapping, and association studies (Marty et al., 2010). In the present study, two of the nine SNPs were in complete linkage, and the D' values of the other seven SNP pairs were greater than 0.90 . Therefore, the 168.5-170.0 Mb region in GGA1 was in LD. LD is weakened with increased genetic distance between genetic loci (Hosomichi et al., 2008; Abasht et al., 2009). In this study, the general trend indicated that the D' value increased with increased distance between SNPs. However, several SNPs were in linkage with other distant SNPs instead of with close SNPs, which suggested that linkage between SNPs was not only related to distance but was also influenced by other factors such as the recombination rate.

Haplotype analyses for nine SNPs showed that the region was in LD. The frequency of haplotype TTTCCTCAC reached $32.4 \%$, which indicated that this haplotype was important for Jinghai yellow chicken growth traits. According to the results of bioinformatic analyses, we found that most of the candidate genes played important roles in different pathways. The pathway analysis showed that SETDB2 and FOXO1 participated in one pathway and six pathways, respectively, and the pathways of the other four genes were unknown but should be further studied. SETDB2 was mainly studied in zebrafish, and Xu et al. (2010) reported that SETDB2 possessed potential transcriptional repression activity through catalyzing trimethylation at histone $\mathrm{H} 3$ lysine 9 (H3K9me3). Moreover, SETDB2 restricted dorsal organizer formation and regulated left-right asymmetry by suppressing fgf8a activity (Xu et al., 2010). Further results indicated that SETDB2 was also a novel regulator for C\&E movements, and it acted by modulating the $d v r 1$ expression level (Xu et al., 2010; Du et al., 2014). Karyopherin alpha 3 gene (KPNA3) belonged to the karyopherin (also known as importin) alpha protein family that functions in the transportation of proteins from the cytoplasm to the nucleus. The alpha karyopherins bind the nuclear localization signals of target proteins for transport from the cytoplasm to the nucleus (Reichelt et al., 1990; Ribbeck et al., 1998). 
A previous study demonstrated that SNPs in KPNA3 were associated with chicken growth traits (Li et al., 2011). Deleted in lymphocytic leukemia 7 gene (DLEU7) encodes a protein containing 221 amino acids, and DLEU7 expression is regulated by the fibroblast growth factor (FGF) pathway during early embryogenesis (Zhu et al., 2012). Moreover, GWAS results showed that the gene was associated with human height (Weedon et al., 2008; Sovio et al., 2009; Kang et al., 2010), which indicated that it might play an important role in chicken growth. ATP7B (a member of the P1B-subfamily of the P-type ATPases) plays an important role in normal brain copper homeostasis, which is likely due to the central role that copper plays in a complex network of signaling pathways that regulate several physiological and pathophysiological processes. Therefore, ATP7B might significantly influence both physiological and pathophysiological processes (Telianidis et al., 2013). Integrator complex subunit 6 gene (INTS6) is a negative regulator of vertebrate organizer gene expression, and it was reported that INTS6 confined the organizer to dorsal domains, preventing it from extending around the margin into ventral domains (Kapp et al., 2013). Moreover, Xie et al. (2012) reported that a SNP in INTS6 was significantly associated with body weight at 90 days in F2 chickens. FOXO1 is a member of the FOXO forkhead transcription factors, and it was involved in myogenic growth and differentiation (Leger et al., 2006; Kitamura et al., 2007; Southgate et al., 2007; Yuan et al., 2011), and the overexpression of this gene resulted in weight loss and reduced skeletal muscle mass in both mice and rats (Kamei et al., 2004; Cho et al., 2010). The results of the above studies showed that the six candidate genes, especially KPNA3, INTS6, and FOXO1, might have significant influence on chicken growth traits.

\section{Conflicts of interest}

The authors declare no conflict of interest.

\section{ACKNOWLEDGMENTS}

Research supported by the National Broiler Industrial and Technology System (\#nycytx42-G1-05), the Priority Academic Program Development of Jiangsu Higher Education Institutions, the Graduate Education Innovation Project in Jiangsu Province (\#CXLX12_0930), and the Excellent Doctor Degree Dissertation Foundation of Yangzhou University.

\section{REFERENCES}

Abasht B, Sandford E, Arango J, Settar P, et al. (2009). Extent and consistency of linkage disequilibrium and identification of DNA markers for production and egg quality traits in commercial layer chicken populations. BMC Genomics 10: S2.

Cardon LR and Bell JI (2001). Association study designs for complex diseases. Nat. Rev. Genet. 2: 91-99.

Cho JE, Fournier M, Da X and Lewis MI (2010). Time course expression of Foxo transcription factors in skeletal muscle following corticosteroid administration. J. Appl. Physiol. 108: 137-145.

Du TT, Xu PF, Dong ZW, Fan HB, et al. (2014). Setdb2 controls convergence and extension movements during zebrafish gastrulation by transcriptional regulation of $d v r 1$. Dev. Biol. 392: 233-244.

Gu X, Feng C, Ma L, Song C, et al. (2011). Genome-wide association study of body weight in chicken F2 resource population. PLoS One 6: e21872.

Hosomichi K, Miller MM, Goto RM, Wang Y, et al. (2008). Contribution of mutation, recombination, and gene conversion to chicken MHC-B haplotype diversity. J. Immunol. 181: 3393-3399.

Kamei Y, Miura S, Suzuki M, Kai Y, et al. (2004). Skeletal muscle FOXO1 (FKHR) transgenic mice have less skeletal muscle mass, down-regulated Type I (slow twitch/red muscle) fiber genes, and impaired glycemic control. J. Biol. Chem. 279: 41114-41123. 
Kang SJ, Chiang CW, Palmer CD, Tayo BO, et al. (2010). Genome-wide association of anthropometric traits in African- and African-derived populations. Hum. Mol. Genet. 19: 2725-2738.

Kapp LD, Abrams EW, Marlow FL and Mullins MC (2013). The integrator complex subunit 6 (Ints6) confines the dorsal organizer in vertebrate embryogenesis. PLoS Genet. 9: e1003822.

Kitamura T, Kitamura YI, Funahashi Y, Shawber CJ, et al. (2007). A Foxo/Notch pathway controls myogenic differentiation and fiber type specification. J. Clin. Invest. 117: 2477-2485.

Leger B, Cartoni R, Praz M, Lamon S, et al. (2006). Akt signalling through GSK-3beta, mTOR and Foxo1 is involved in human skeletal muscle hypertrophy and atrophy. J. Physiol. 576: 923-933.

Li C, Wang X, Wang G, Wu C, et al. (2011). Genome-wide expression analysis of roxarsone-stimulated growth of broiler chickens (Gallus gallus). Comp. Biochem. Physiol. Part D Genomics Proteomics 6: 264-270.

Li DF, Lian L, Qu LJ, Chen YM, et al. (2013). A genome-wide SNP scan reveals two loci associated with the chicken resistance to Marek's disease. Anim. Genet. 44: 217-222.

Liu R, Sun Y, Zhao G, Wang F, et al. (2013). Genome-wide association study identifies loci and candidate genes for body composition and meat quality traits in Beijing-You chickens. PLoS One 8: e61172.

Liu W, Li D, Liu J, Chen S, et al. (2011). A genome-wide SNP scan reveals novel loci for egg production and quality traits in white leghorn and brown-egg dwarf layers. PLoS One 6: e28600.

Liu X, Zhang H, Li H, Li N, et al. (2008). Fine-mapping quantitative trait loci for body weight and abdominal fat traits: effects of marker density and sample size. Poult. Sci. 87: 1314-1319.

Lu SX and Wu CX (2002). Research and application of animal genetic marker-assisted selection. Yi Chuan 24: 359-362.

Luo C, Qu H, Ma J, Wang J, et al. (2013). Genome-wide association study of antibody response to Newcastle disease virus in chicken. BMC Genet. 14: 42.

Marty A, Amigues Y, Servin B, Renand G, et al. (2010). Genetic variability and linkage disequilibrium patterns in the bovine DNAJA1 gene. Mol. Biotechnol. 44: 190-197.

Noorai RE, Freese NH, Wright LM, Chapman SC, et al. (2012). Genome-wide association mapping and identification of candidate genes for the rumpless and ear-tufted traits of the Araucana chicken. PLoS One 7: e40974.

Reichelt R, Holzenburg A, Buhle EL Jr, Jarnik M, et al. (1990). Correlation between structure and mass distribution of the nuclear pore complex and of distinct pore complex components. J. Cell Biol. 110: 883-894.

Ribbeck K, Lipowsky G, Kent HM, Stewart M, et al. (1998). NTF2 mediates nuclear import of Ran. EMBO J. 17: 6587-6598.

Shi YY and Lin HE (2005). Shesis, a powerful software platform for analyses of linkage disequilibrium, haplotype construction, and genetic association at polymorphism loci. Cell Res. 15: 97-98.

Southgate RJ, Neill B, Prelovsek O, El-Osta A, et al. (2007). FOXO1 regulates the expression of 4E-BP1 and inhibits mTOR signaling in mammalian skeletal muscle. J. Biol. Chem. 282: 21176-21186.

Sovio U, Bennett AJ, Millwood IY, Molitor J, et al. (2009). Genetic determinants of height growth assessed longitudinally from infancy to adulthood in the northern Finland birth cohort 1966. PLoS Genet. 5: 1000409.

Tao Y, Li GH, Hu YP, Mekki MD, et al. (2008). Genetic effects of MC4R and POU1F1 gene on the growth performance in Jinghai yellow chicken. Yi Chuan 30: 900-906.

Telianidis J, Hung YH, Materia S and Fontaine SL (2013). Role of the P-Type ATPases, ATP7A and ATP7B in brain copper homeostasis. Front. Aging Neurosci. 5: 44.

Uemoto Y, Sato S, Odawara S, Nokata H, et al. (2009). Genetic mapping of quantitative trait loci affecting growth and carcass traits in F2 intercross chickens. Poult. Sci. 88: 477-482.

Wahlberg P, Carlborg O, Foglio M, Tordoir X, et al. (2009). Genetic analysis of an F(2) intercross between two chicken lines divergently selected for body-weight. BMC Genomics 10: 248.

Weedon MN, Lango H, Lindgren CM, Wallace C, et al. (2008). Genome-wide association analysis identifies 20 loci that influence adult height. Nat. Genet. 40: 575-583.

Wolc A, Arango J, Settar P, Fulton JE, et al. (2012). Genome-wide association analysis and genetic architecture of egg weight and egg uniformity in layer chickens. Anim. Genet. 1: 87-96.

Xie L, Luo C, Zhang C, Zhang R, et al. (2012). Genome-wide association study identified a narrow chromosome 1 region associated with chicken growth traits. PLoS One 7: e30910.

Xu PF, Zhu KY, Jin Y, Chen Y, et al. (2010). Setdb2 restricts dorsal organizer territory and regulates left-right asymmetry through suppressing fgf8 activity. Proc. Natt. Acad. Sci. U. S. A. 107: 2521-2526.

Yuan Y, Shi XE, Liu YG and Yang GS (2011). FoxO1 regulates muscle fiber-type specification and inhibits calcineurin signaling during C2C12 myoblast differentiation. Mol. Cell Biochem. 348: 77-87.

Zane L, Bargelloni L and Patarnello T (2002). PopGene32, Microsoft windows-based freeware for population geneticanalysis. Version 1.32. Molecular Biology and Biotechnology Centre, University of Alberta, Edmonton.

Zhu X, Li Z, Jiang D, Zhao J, et al. (2012). Characterization and expressional analysis of Dleu7 during Xenopus tropicalis embryogenesis. Gene 509: 77-84. 